\title{
Evaluasi Pencahayaan Alami Ruang Kelas di Areal Pesisir Pantai Sulawesi Selatan
}

\author{
* Irnawaty Idrus ${ }^{1}$, Ramli Rahim ${ }^{2}$, Baharuddin Hamzah ${ }^{2}$, Rosady Mulyadi ${ }^{2}$, Nurul Jamala ${ }^{2}$ \\ ${ }^{1}$ Program Studi Arsitektur, Fakultas Teknik, Universitas Muhammadiyah Makassar, Indonesia \\ ${ }^{2}$ Departemen Arsitektur, Fakultas Teknik, Universitas Hasanuddin, Indonesia \\ Alamat Email: irnawatyidrus@unismuh.ac.id
}

*Alamat korespondensi, Masuk: 3 Mar. 2019, Direvisi: 15 Jun. 2019, Diterima: 28 Jun. 2019

\begin{abstract}
ABSTRAK: Penelitian ini dilakukan untuk mengidentifikasi intensitas pencahayaan alami pada bangunan sekolah dasar di wilayah pesisir Sulawesi Selatan, dan kemudian meninjau kesesuaiannya dengan standar pencahayaan alami bangunan. Penelitian ini merupakan langkah awal dari upaya konservasi energi dengan pemanfaatan cahaya alami sebagai sumber pencahayaan bangunan, utamanya untuk ruang-ruang kelas yang hanya dipergunakan pada pagi hingga sore hari. Metode penelitian ini yaitu kuantitatif yang datanya diperoleh melalui survei dan pengukuran langsung di lokasi penelitian. Ada enam sekolah dasar di wilayah pesisir Sulawesi Selatan yang dijadikan sampel penelitian. Sekolah-sekolah tersebut berlokasi di Kabupaten Barru, Pare-Pare dan Pinrang. Sampel dipilih secara purposive sampling. Hasil penelitian menunjukkan sebagian besar intensitas cahaya alami ruang kelas sekolah dasar di areal pesisir pantai Sulawesi Selatan berada di bawah standar pencahayaan rata-rata SNI ruang kelas. Sebanyak 83,2\% dibawah nilai standar pencahayaan rata-rata SNI untuk ruang kelas dan hanya sebanyak 16,8\% yang memenuhi nilai standar SNI.
\end{abstract}

Kata kunci: Intensitas, Pencahayaan Alami, Ruang Kelas, Konservasi Energi

\begin{abstract}
This study aims to identify the intensity of natural lighting in elementary school buildings in the coastal area of South Sulawesi, and then review their compatibility with the building's natural lighting standards. This research is the first step of energy conservation efforts by utilizing natural light as a source of lighting for buildings, especially for classrooms that are only used in the morning to evening. This research method is quantitative, the data obtained through surveys and direct measurements at the research location. There are six elementary schools in the coastal area of South Sulawesi that are used as research samples. The schools are located in Barru, Pare-Pare and Pinrang districts. Samples were selected by purposive sampling. The results showed that most of the natural light intensity of elementary school classrooms in the coastal area of South Sulawesi was below the average SNI lighting standards for classrooms. As many as $83.2 \%$ below the average lighting standard value of SNI for classrooms and only as much as $16.8 \%$ that meet the SNI standard value.
\end{abstract}

Keywords: Intensity, Daylighting, Classrooms, Energy Conservation

\section{PENDAHULUAN}

Pada suatu kawasan, bangunan sekolah merupakan salah satu fasilitas publik yang menunjang aktivitas pendidikan. Sebagai bangunan publik, biaya yang dikeluarkan untuk operasional sekolah berasal dari masyarakat dan juga pemerintah, oleh karena itu upaya penghematan energi dapat memberi dampak yang cukup baik bagi banyak pihak. Konsep bangunan hemat energi merupakan tren desain bangunan pada saat ini, hal tersebut merupakan respons terhadap keprihatinan akan penggunaan energi secara global, sektor bangunan menyerap $45 \%$ dari kebutuhan energi secara global. Salah satu metode dalam arsitektur hemat energi yaitu mengoptimasikan sistem tata cahaya, integrasi antara sistem tata cahaya buatan- alamiah serta sinergi antara metode pasif dan aktif baik secara manual ataupun otomatis [1].

Pencahayaan alami siang hari dimaksudkan untuk memperoleh pencahayaan di dalam bangunan pada siang hari dari cahaya alami. Manfaat pencahayaan alami dapat memberikan lingkungan visual yang menyenangkan dan nyaman dengan kualitas cahaya yang mirip kondisi alami di luar bangunan. Selain itu juga dapat mengurangi atau bahkan meniadakan pencahayaan buatan sehingga dapat mengurangi penggunaan listrik [2].

Sebagai daerah tropis, Indonesia memiliki potensi pencahayaan alami yang sangat besar. Menurut penelitian mengenai pengukuran durasi penyinaran matahari di kota Makassar yang 
merupakan salah satu wilayah pesisir provinsi Sulawesi Selatan, frekuensi kejadian langit cerah (clear sky) sebesar $15,14 \%$, langit berawan (intermediate sky) sebesar $69,78 \%$ dan langit mendung (overcast sky) sebesar 15,08\% [3]. Nilai standar penerangan horizontal dari langit yang tidak terhalang merupakan hal yang sangat penting dan mendasar untuk konservasi energi di bidang desain pencahayaan. Penelitian mengenai iluminansi langit yang berasal dari pengumpulan data iluminasi difus di Makassar mulai tahun 1995 sampai dengan 2000, menyatakan bahwa nilai iluminansi horizontal dari langit yang tidak terhalang adalah 14,35 $\mathrm{Klx}$ [4]. Hal tersebut menunjukkan peluang yang besar bagi bangunan khususnya di wilayah pesisir Sulawesi Selatan untuk memanfaatkan pencahayaan alami siang hari sebagai upaya penghematan energi pada bangunan.

Sebagai perencana, selain mempertimbangkan pencahayaan alami sebagai salah satu faktor pendukung untuk menciptakan bangunan hemat energi, harus juga tetap mempertimbangkan kenyamanan beraktivitas sehingga produktivitas kerja dapat semakin meningkat [5]. Kenyamanan pencahayaan juga sangat dipengaruhi oleh fasad bangunan, strategi pasif desain dapat memaksimalkan pencahayaan alami dalam bangunan [6].

Berdasarkan hal itu, maka peneliti merasa penting untuk dapat mengidentifikasi dan mengungkap informasi mengenai intensitas cahaya alami pada ruang kelas dan kesesuaiannya dengan standar nasional pencahayaan bangunan (SNI), khususnya yang berada di kabupaten Maros, Pangkep, Barru, Pare-Pare dan Pinrang sebagai lokasi studi. Informasi yang diperoleh akan menjadi acuan dalam menyusun langkah-langkah optimalisasi atau sebagai data awal penelitian mengenai tingkat kenyamanan visual di ruang kelas.

\section{BAHAN DAN METODE PENELITIAN Pengujian Pencahayaan Alami}

Pengujian pencahayaan alami dilakukan untuk mengetahui intensitas cahaya alami pada suatu ruang. Nilai pengujian tersebut akan disesuaikan dengan standar baku pencahayaan yang telah ditetapkan. Pada SNI 03-2396-2001 diatur mengenai langkah pengujian pencahayaan alami [7], yaitu dapat dilakukan dengan mengukur atau memeriksa:

1. Tingkat Pencahayaan

a. Tingkat pencahayaan di Titik Ukur Utama (TUU), Titik Ukur Samping (TUS), titik di luar ruangan di tempat terbuka dan pengukuran dilakukan pada waktu yang bersamaan.

b. Menghitung faktor langit pada TUU dan TUS

2. Indeks Kesilauan

Nilai tingkat pencahayaan dapat diukur langsung dengan menggunakan alat ukur. Alat untuk mengukur tingkat pencahayaan/ iluminasi dinamakan luksmeter. Nilai yang menjadi standar tingkat pencahayaan dapat dilihat pada Tabel 1 [8].

Tabel 1. Tingkat Pencahayaan Rata-Rata yang Direkomendasikan

\begin{tabular}{lc}
\hline \multicolumn{1}{c}{ Fungsi Ruangan } & $\begin{array}{c}\text { Tingkat } \\
\text { Pencahayaan (lux) }\end{array}$ \\
\hline Lembaga Pendidikan: & \\
Ruang Kelas & 250 \\
Perpustakaan & 300 \\
Laboratorium & 500 \\
Ruang Gambar & 750 \\
Kantin & 200 \\
\hline
\end{tabular}

(Sumber: SNI 03-6197-2000)

Setiap kelas pada umumnya menggunakan media papan tulis, biasanya menggunakan blackboard ataupun whiteboard. Harus diperhatikan mengenai pencahayaannya, agar tidak menimbulkan masalah penglihatan bagi siswa karena adanya pantulan cahaya, utamanya siswa yang posisi duduknya dekat papan tulis. Kuat pencahayaan yang disarankan untuk media whiteboard adalah 250 lux, sedangkan kuat pencahayaan yang disarankan untuk blackboard yang daya pantulnya tidak lebih dari 0,1 adalah 500 lux. Sedangkan ruang kelas yang menggunakan media LCD, disarankan kuat pencahayaan umumnya adalah 250-300 lux dengan menyediakan dimmer untuk mengatasi masalah pencahayaan (glare) yang timbul [9].

Penelitian ini merupakan penelitian kuantitatif. Dalam penelitian ini, data yang diperoleh dari observasi dan pengukuran akan dibandingkan dengan ketentuan standar nasional yang mengatur mengenai pencahayaan bangunan (SNI).

Ada enam sekolah yang menjadi sampel penelitian. Pemilihan sampel melalui metode Purposive Sampling. Pada setiap kabupaten, dipilih dua sekolah yang menjadi sampel penelitian. Sekolah tersebut adalah SD Inpres Awerange, SD Inpres Batupute, SDN 9 Bujung Tangaya, SDN 20 Bujung Tangaya, SDN 29 Pare-Pare, dan SDN 30 Pare-Pare. Pada tiap sekolah, pengukuran dilakukan 
pada tiga kelas. Waktu pengukuran yaitu pagi hingga siang hari. Adapun langkah-langkah yang dilakukan dalam penelitian ini antara lain:

1. Pendataan Kondisi Ruang Kelas.

Data yang dikumpulkan antara lain dimensi kelas, warna dinding, lantai dan plafon, layout kelas, orientasi kelas, dimensi dan material bukaan, elevasi lantai, dan waktu pengukuran.

\section{Pendataan Kondisi Cuaca}

Data yang dikumpulkan adalah kondisi langit pada saat pengukuran. Metode yang dipakai adalah pengamatan (observasi) langsung terhadap jumlah awan. Pengelompokan dinyatakan dalam jumlah awan yang menutupi langit yang diberi satuan octas, dinyatakan dalam angka 0 sampai 8 . Langit tanpa awan (clear sky) adalah 0-1 octas, langit yang sebagian tertutup awan (intermediate sky) adalah 26 octas, dan langit yang seluruhnya tertutup awan (overcast sky) adalah 7-8 octas [2].

3. Pendataan Intensitas Cahaya Alami Intensitas cahaya diukur dengan menggunakan alat HOBO Data Logger with external sensor yang mempunyai fungsi antara lain mengukur dan menyimpan data temperatur udara, kelembaban udara, intensitas cahaya, dan kecepatan angin dalam ruang [10-12].

\section{Analisis Data}

Data yang diperoleh di lapangan, kemudian diinput dan dianalisis dengan menggunakan software statistik SPSS. Pada penelitian ini, teknik analisis data yang digunakan adalah Statistik Deskriptif.

\section{HASIL DAN PEMBAHASAN}

SD Inpres Awerangnge dan SD Inpres Batupute Kabupaten Barru

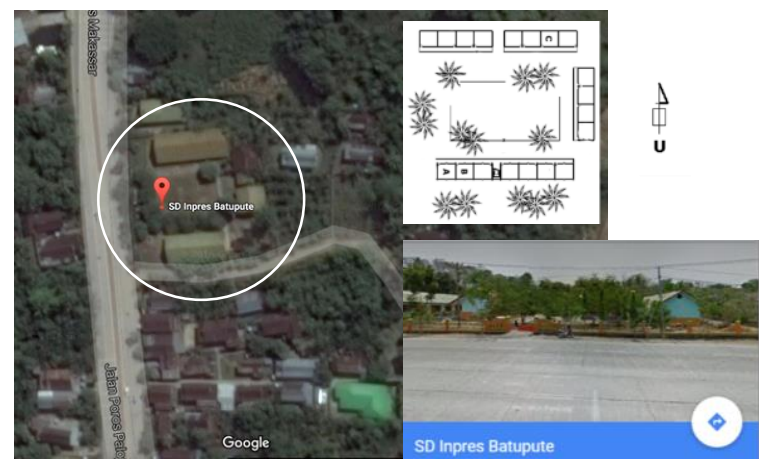

Gambar 1. Lokasi SD Inpres Batupute

Kabupaten Barru merupakan salah satu Kabupaten yang berada di pesisir Barat Provinsi Sulawesi Selatan, dengan Ibu Kota Sumpang Binangae terletak antara koordinat $4^{\circ} 00^{\prime}-5^{\circ} 35^{\prime}$ Lintang Selatan dan $199^{\circ} 35^{\prime}$ - 119 $49^{\circ}$ Bujur Timur.
Luas wilayah daratan kurang lebih 1.174,72 km2 $(117.427 \mathrm{Ha})$ dan perairan $56.160 \mathrm{Ha}$. Lokasi penelitian berada di jalan Poros Makassar-Palopo yang berjarak $124 \mathrm{~km}$ dari Kota Makassar. Jarak dengan pinggir pantai sejauh 138 meter.

Sekolah SD Inpres Awerange dan Batupute masing-masing terdiri dari 3 unit bangunan. Setiap ruang kelas memiliki luas ruangan sebesar $56 \mathrm{~m}^{2}$ dan terdapat siswa/i rata-rata sebanyak 20 orang. Bukaan kelas yang menjadi objek penelitian pada SD Awerange dan SD Inpres Batupute berorientasi Utara-Selatan.

Pengambilan data pada SD Inpres Awerange dan SD Inpres Batupute dilakukan pada masingmasing tiga ruang kelas. Enam kelas yang menjadi sampel memiliki orientasi bukaan yang sama. Bukaannya terletak pada sisi Utara dan Selatan ruang kelas. Pengukuran dilakukan pada tanggal 29 Oktober 2016. Waktu pengukuran yaitu pukul 09.00 sampai dengan 13.00. Cuaca pada saat pengukuran Cerah. Hasil pengukuran menunjukkan $100 \%$ data intensitas cahaya alami dalam ruang kelas sekolah dasar di kabupaten Barru dibawah standar SNI pencahayaan rata-rata $250 l u x$. Tingkat intensitas minimal dalam kelas yaitu 39,45 lux, dan intensitas cahaya maksimum yaitu 149,75 lux.

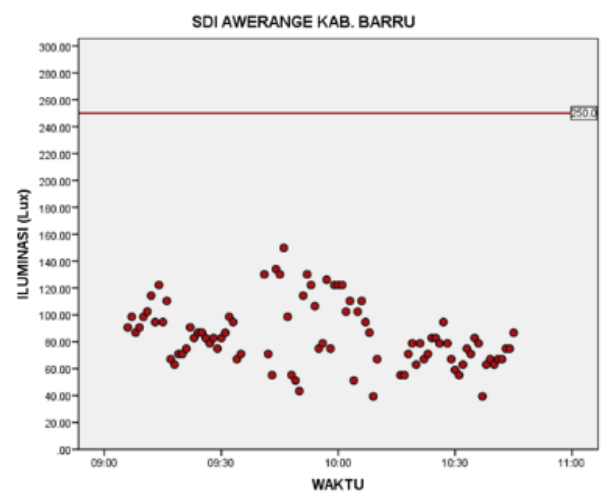

Gambar 2. Grafik Intensitas Cahaya Alami SD Inpres Awerange Kabupaten Barru

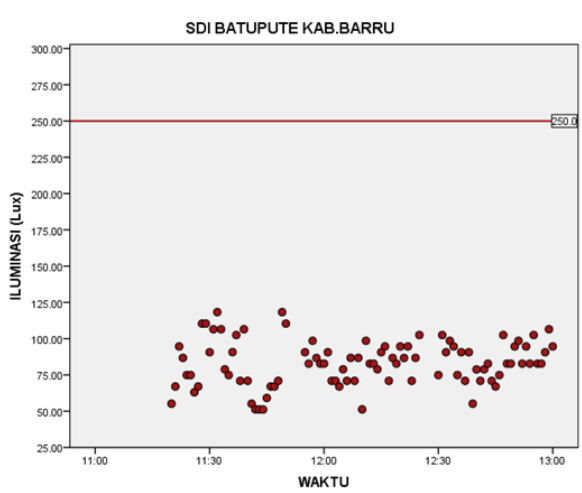

Gambar 3. Grafik Intensitas Cahaya Alami SD Inpres Batupute Kabupaten Barru 
SD Negeri 29 dan SD Negeri 30 Kota Pare-Pare

Kota Parepare secara geografis berada pada posisi $4^{\circ} 01^{\prime} 00^{\prime \prime} \mathrm{S} ; 1^{\circ} 9^{\circ} 37^{\prime} 25^{\prime \prime} \mathrm{E}$. Secara administrasi wilayah kota Parepare memiliki batasan dengan beberapa kabupaten sebagai berikut: Sebelah Selatan berbatasan dengan kabupaten Pinrang, Sebelah timur berbatasan dengan Kabupaten Sidenreng Rappang, Sebelah Selatan berbatasan dengan kabupaten Barru, Sebelah barat berbatasan dengan selat Makassar. Kota Parepare terdiri dari 4 kecamatan dan 22 kelurahan.

Lokasi penelitian yaitu di SDN 29 dan SDN 30 Pare-Pare. Terletak di Jln. Tentara Pelajar kota Pare-Pare.
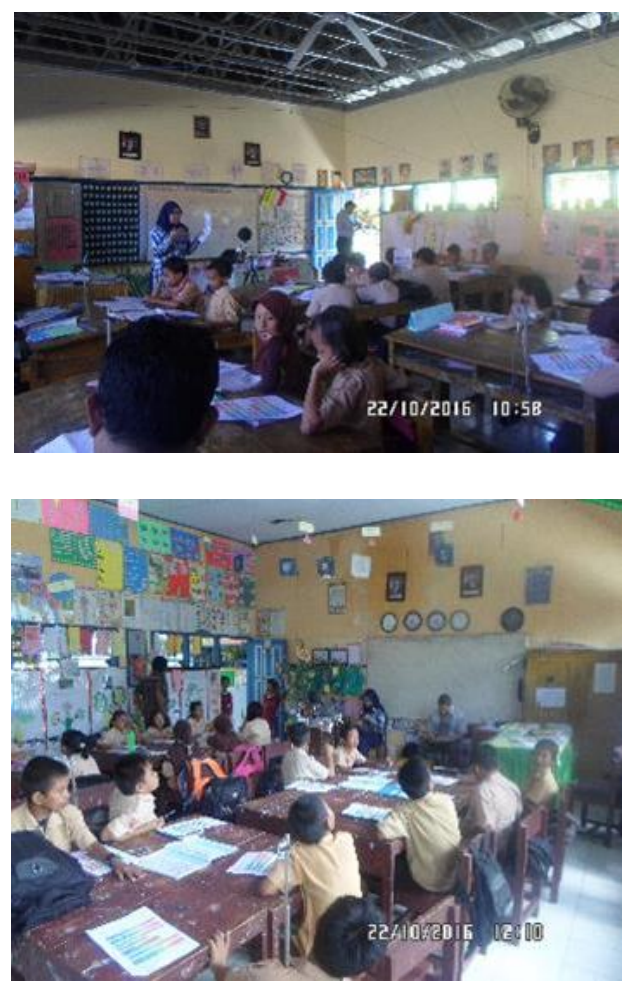

Gambar 4. Pengukuran Intensitas cahaya pada SD Negeri 29 dan SD Negeri 30 Pare-Pare

Pengukuran pada kelas dilakukan pada hari Sabtu 22 Oktober 2016 mulai pagi hari pukul 08.00 hingga siang hari pukul 12.30. Pengukuran dilakukan pada empat kelas yang sebagian besar berorientasi Timur-Barat. Luas setiap kelas adalah $7 \mathrm{~m} \times 8 \mathrm{~m}(56 \mathrm{~m} 2)$, tipe bangunan permanen dengan dinding batu bata di plester, atap menggunakan seng. Cuaca pada saat pengukuran Cerah.

Hasil pengukuran menunjukkan $91 \%$ data intensitas cahaya alami dalam ruang keseluruhan kelas berada di bawah standar SNI pencahayaan rata-rata dalam ruang yaitu 250 lux dan $9 \%$ data yang memenuhi standar SNI. Tingkat intensitas minimal dalam kelas yaitu 27,60 lux dan intensitas cahaya maksimum yaitu 299,60 lux.

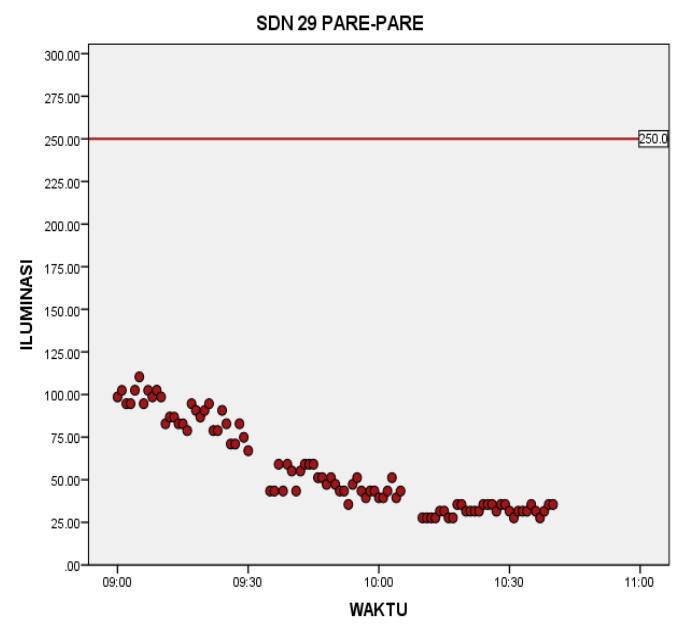

Gambar 5. Grafik Intensitas Cahaya Alami SD Negeri 29 Kota Pare-Pare

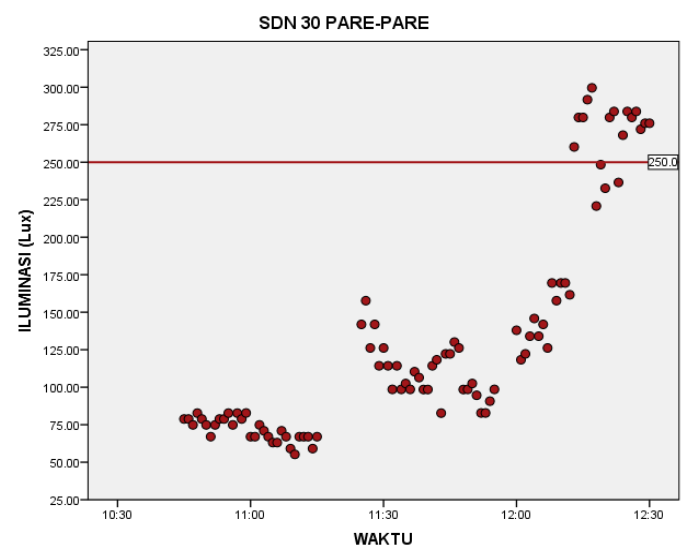

Gambar 6. Grafik Intensitas Cahaya Alami SD Negeri 30 Kota Pare-Pare

\section{SDN 59 Lanrisang dan SDN 178 Lanrisang Kabupaten Pinrang}

Kabupaten Pinrang dengan ibukota Pinrang terletak disebelah $185 \mathrm{~km}$ utara ibukota Provinsi Sulawesi Selatan, berada pada posisi $3^{\circ} 19^{\prime} 13^{\prime \prime}$ sampai $4^{\circ} 10^{\prime} 30^{\prime \prime}$ lintang selatan dan $119^{\circ} 26^{\prime} 30^{\prime \prime}$ sampai $119^{\circ} 47^{\prime} 20^{\prime \prime}$ bujur timur. Lokasi penelitian yaitu di SD Negeri 178 Kabupaten Pinrang dan SD Negeri 59 Kabupaten Pinrang. Kedua sekolah ini terletak di Kecamatan Lanrisang Kelurahan Lanrisang. Penelitian di SD Negeri 178 Kabupaten Pinrang dilakukan pada tanggal 15 Oktober 2016. Pada umumnya kondisi cuaca pada hari itu Cerah. Pengukuran pada SDN 178 Lanrisang dan SDN 59 Lanrisang dilakukan pada hari Sabtu 15 Oktober 2016 mulai pagi hari pukul 08.40 hingga pukul 12.50 . 
Bukaan pada kelas di SDN 178 Lanrisang terletak pada dua sisi kelas, yaitu pada arah Barat Daya dan Timur Laut. Bukaan pada kelas di SDN 59 Lanrisang terletak pada dua sisi kelas, yaitu pada arah Barat Laut dan Timur Tenggara.

Hasil pengukuran menunjukkan $100 \%$ data intensitas cahaya alami dalam ruang kelas pada pengukuran di SDN 59 Lanrisang memenuhi standar SNI. Pada lokasi penelitian di SDN 178 Lanrisang, sekitar $16 \%$ data yang memenuhi SNI dan $82 \%$ yang tidak memenuhi Standar SNI. Tingkat intensitas minimal dalam kelas di SDN 59 Lanrisang yaitu 260,15 lux dan intensitas cahaya maksimum yaitu 406,05 lux.

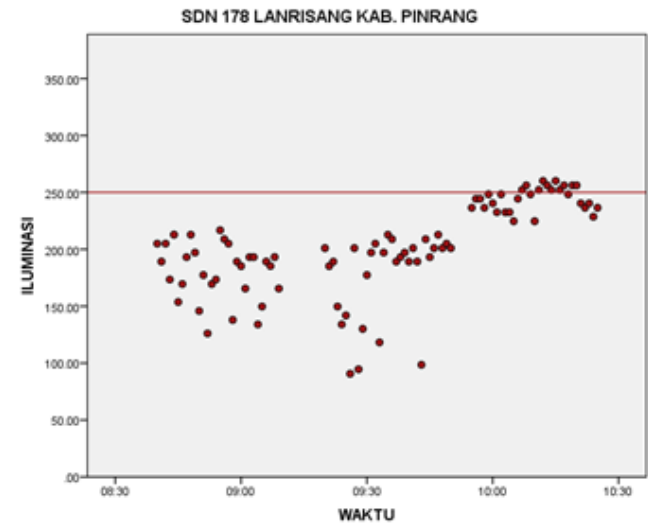

Gambar 7. Grafik Intensitas Cahaya Alami SDN 178 Lanrisang, Pinrang

\section{KESIMPULAN DAN SARAN}

Dari penelitian yang telah dilakukan, dapat diidentifikasi tingkat intensitas pencahayaan alami ruang kelas pada sekolah-sekolah yang menjadi sampel penelitian. Dari data yang diperoleh, sebagian besar intensitas cahaya ruang kelas sekolah dasar di wilayah pesisir Sulawesi Selatan masih dibawah standar SNI. Sebanyak 83,2\% dibawah nilai standar pencahayaan rata-rata $\mathrm{SNI}$ untuk ruang kelas dan hanya sebanyak 16,8\% yang memenuhi nilai standar SNI.
Tabel 1. Nilai Intensitas Cahaya Alami Ruang Kelas di Areal Pesisir Pantai Sulawesi Selatan

\begin{tabular}{llllc}
\hline \multicolumn{4}{c}{ Descriptive Statistics } \\
\hline & N & Min & Max & $\begin{array}{c}\text { Std. } \\
\text { Deviation } \\
\end{array}$ \\
ILUMINASI & 554 & 27.60 & 406.05 & 110.29874 \\
$\begin{array}{l}\text { Valid N } \\
\text { (listwise) }\end{array}$ & 554 & & & \\
\hline
\end{tabular}

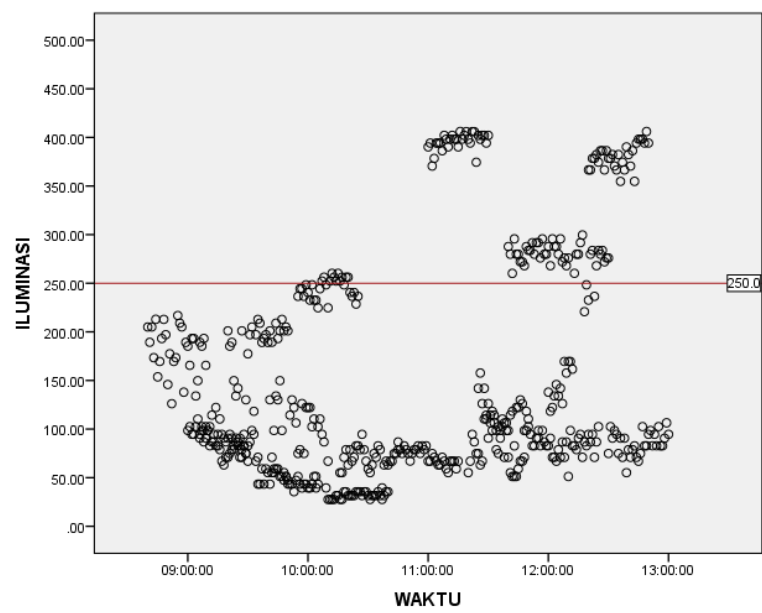

Gambar 8. Grafik Intensitas Cahaya Alami Ruang Kelas di Areal Pesisir Pantai Sulawesi Selatan

Dari data penelitian, ada satu sekolah yang cahaya alami ruang kelasnya memenuhi standar. Arah orientasi bukaan kelas tersebut adalah Barat Laut dan Timur Tenggara. Hal tersebut dapat menjadi masukan untuk penelitian lebih lanjut mengenai intensitas cahaya alami menurut orientasi bukaan. Rendahnya tingkat intensitas cahaya pada ruang-ruang kelas tersebut, diharapkan juga menjadi acuan bagi peneliti-peneliti selanjutnya, untuk menemukan model khususnya bagi ruang kelas agar dapat mengoptimalisasi penetrasi cahaya alami pada ruang kelas.

\section{DAFTAR PUSTAKA}

[1] Idrus I (2018) EVALUASI KONDISI PENCAHAYAAN INTEGRASI MANUAL PADA RUANG KANTOR MENARA BALAIKOTA MAKASSAR. Jurnal LINEARS Vol. 1, No. 1: hal. 1-11.

[2] Soegijanto (1999) Bangunan di Indonesia dengan iklim tropis lembab ditinjau dari aspek fisika bangunan: Direktorat Jenderal Pendidikan Tinggi, Departemen Pendidikan dan Kebudayaan. ISBN: 9798439082.

[3] Rahim R, Mulyadi R (2004) Classification of daylight and radiation data into three sky conditions by cloud ratio and sunshine duration. Energy Buildings Vol. 36, No. 7: hal. 660-666.

[4] Mulyadi R, Jamala N, Rahim R (2007) An examination on daily horizontal illuminance data in Indonesia. 8th SENVAR 2nd MALAY, Surabaya, Indonesia

[5] Jamala N (2015) ANALISIS PENCAHAYAAN BANGUNAN HEMAT ENERGI (Studi Kasus: Gedung Wisma Kalla di Makassar). Jurnal Penelitian dan Karya Ilmiah Arsitektur Usakti Vol. 15, No. 2. 
[6] Jamala N (2017) The effect of building façade on natural lighting (Case study: Building of phinisi tower UNM). AIP Conference Proceedings. AIP Publishing LLC. hal. 020061.

[7] Indonesia SNJBSN (2001) Tata cara perancangan sistem pencahayaan alami pada bangunan gedung.

[8] Nasional BS (2000) Konservasi Energi Sistem Pencahayaan Pada Bangunan Gedung. SNI 03-6197-2000.

[9] Bean R (2014) Lighting: interior and exterior: Routledge. ISBN: 1317935152.

[10] Latif S, Rahim R, Hamzah B (2016) Analisis Kenyamanan Termal Siswa di Dalam Ruang Kelas (Studi Kasus SD Inpres Tamalanrea IV Makassar). Simposium Nasional Rekayasa Aplikasi Perancangan dan Industri (RAPI XV); 7 Desember; Hotel Alila, Surakarta. hal. 466-473.

[11] Latif S, Hamzah B, Rahim R, et al. (2019) Computational Study of the Heat Ventilation on The Attics of Buginese Houses. 1st International Conference on Science and Technology, ICOST 2019. European Alliance for Innovation (EAI).

[12] Idrus I, Hamzah B, Mulyadi R (2016) Intensitas pencahayaan alami ruang kelas sekolah dasar di kota makassar. Simposium Nasional Rekayasa Aplikasi Perancangan dan Industri (RAPI XV); 7 Desember; Hotel Alila, Surakarta. 